\title{
CARPINTARIA NAVAL EM CONTEXTOS DE TERRITÓRIOS DE ASSENTAMENTOS RURAIS RIBEIRINHOS EM ABAETETUBA, PARÁ, BRASIL
}

Rosenildo da Costa Pereira (1D $ه$

Universidade Federal do Pará I Belém - PA - Brasil 
Ainda que timidamente, pesquisas têm sido realizadas acerca do universo do trabalho no/do campo, especificamente voltadas para a agricultura familiar praticada na relação com a terra e/ou a água. Pouco se tem explorado sobre a prática da carpintaria naval existente e executada por ribeirinhos de assentamentos rurais de Abaetetuba, Pará.

Nesse sentido, o presente ensaio busca registrar essa prática social, ainda pouco pesquisada por cientistas. Fazer este registro é compreender como esses sujeitos, que nunca frequentaram uma faculdade de curso de engenharia naval, têm notório saber e domínio sobre o processo de construção de embarcações, usadas no deslocamento cotidiano. Fazer tal descrição é, assim:

[...] pensar nas técnicas que cada um destes utiliza para produzir "seus" objetos, buscando comparar os distintos sistemas de produção, os estilos, bem como a relação que estabelece entre esses elementos e a organização social e do trabalho, suas expressões culturais e simbólicas (Mura 2011:97).

Como diz Mura (2011), as tecnologias oriundas do trabalho de comunidades tradicionais são relevantes para a organização social e do trabalho efetivado a partir do próprio território desses sujeitos.

Apreender os saberes da carpintaria naval como trabalho de comunidades tradicionais praticado no território rural ribeirinho do Assentamento São João Batista é mergulhar em uma teia de tramas de conhecimentos oriundos de experiências de anos, plasmados na relação do ver e do presenciar o ofício do carpinteiro cotidianamente, e transmitidos de geração em geração entre os membros de uma mesma família.

Este ensaio fotográfico tem o importante papel de trazer à tona os saberes que envolvem o fazer da carpintaria naval, apresentando fotos (Figuras 1 a 14) que demarcam cada etapa de construção de embarcações e os processos que a envolvem.

Assim, seguem os registros fotográficos desta atividade de trabalho presente também no território do campo, especificamente do campo ribeirinho do Assentamento São João Batista, em Abaetetuba, Pará.

\section{REFERÊNCIA}

Mura, F. 2011. De sujeitos e objetos: um ensaio crítico de antropologia da técnica e da tecnologia. Horizontes Antropológicos 17(36):95-125. DOI: http:// dx.doi.org/10.1590/S0104-71832011000200005. 


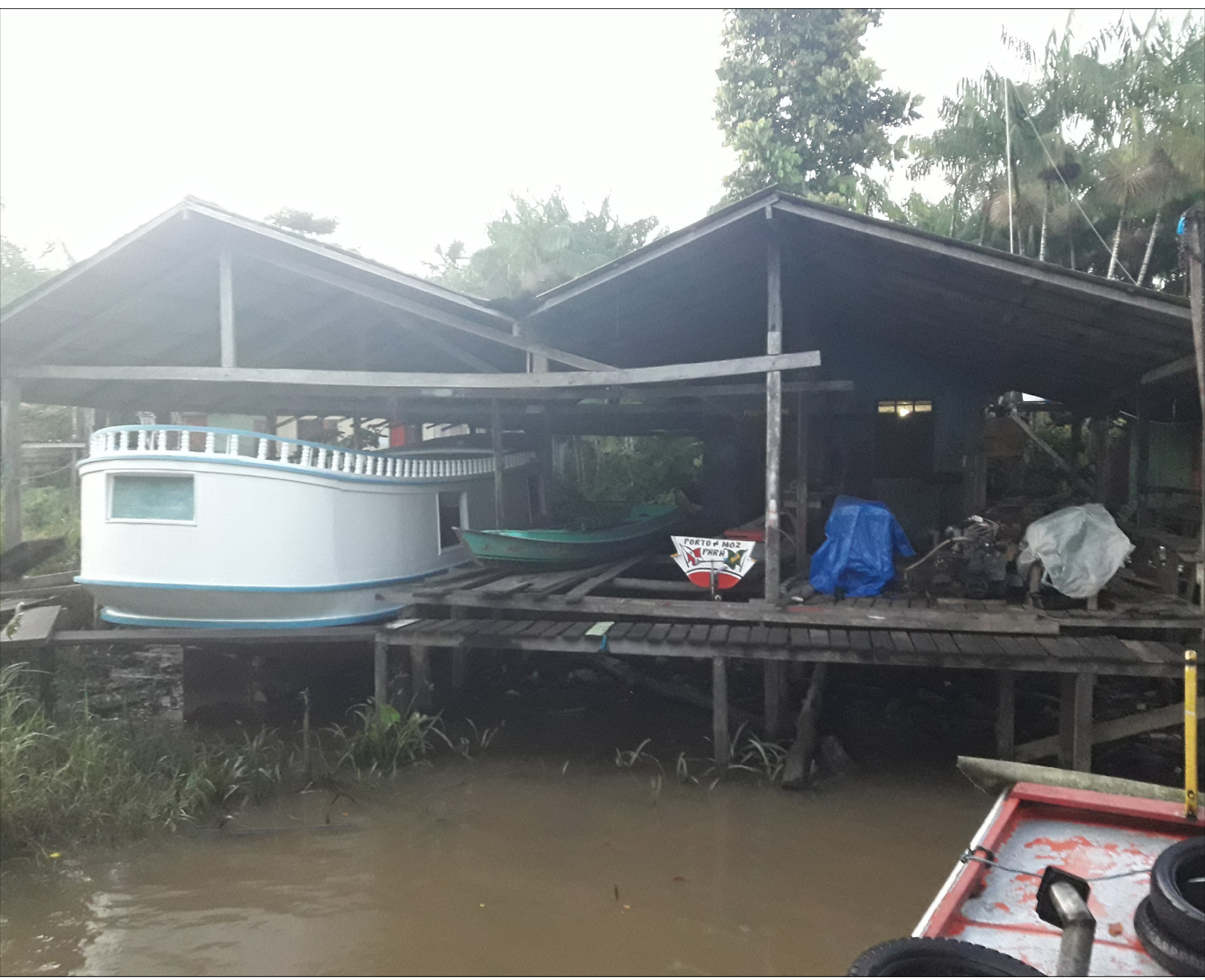

Figura 1 - Estaleiro de construção de rabetas e barcos (ateliê) em Abaetetuba, Pará. Foto: Rosenildo da Costa Pereira (25 maio 2018). 


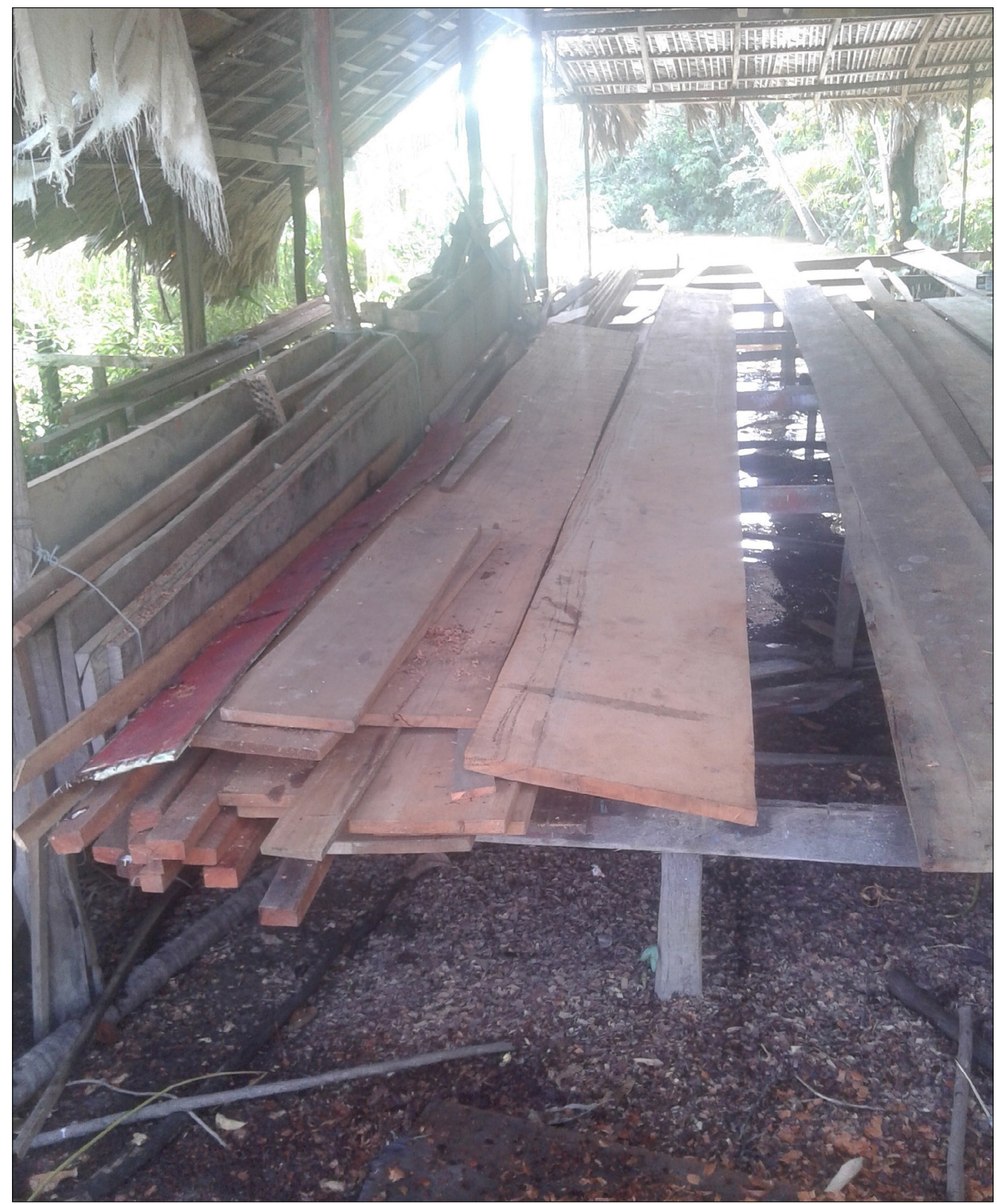

Figura 2 - Madeira usada na confecção das embarcações. Foto: Rosenildo da Costa Pereira (25 nov. 2018). 


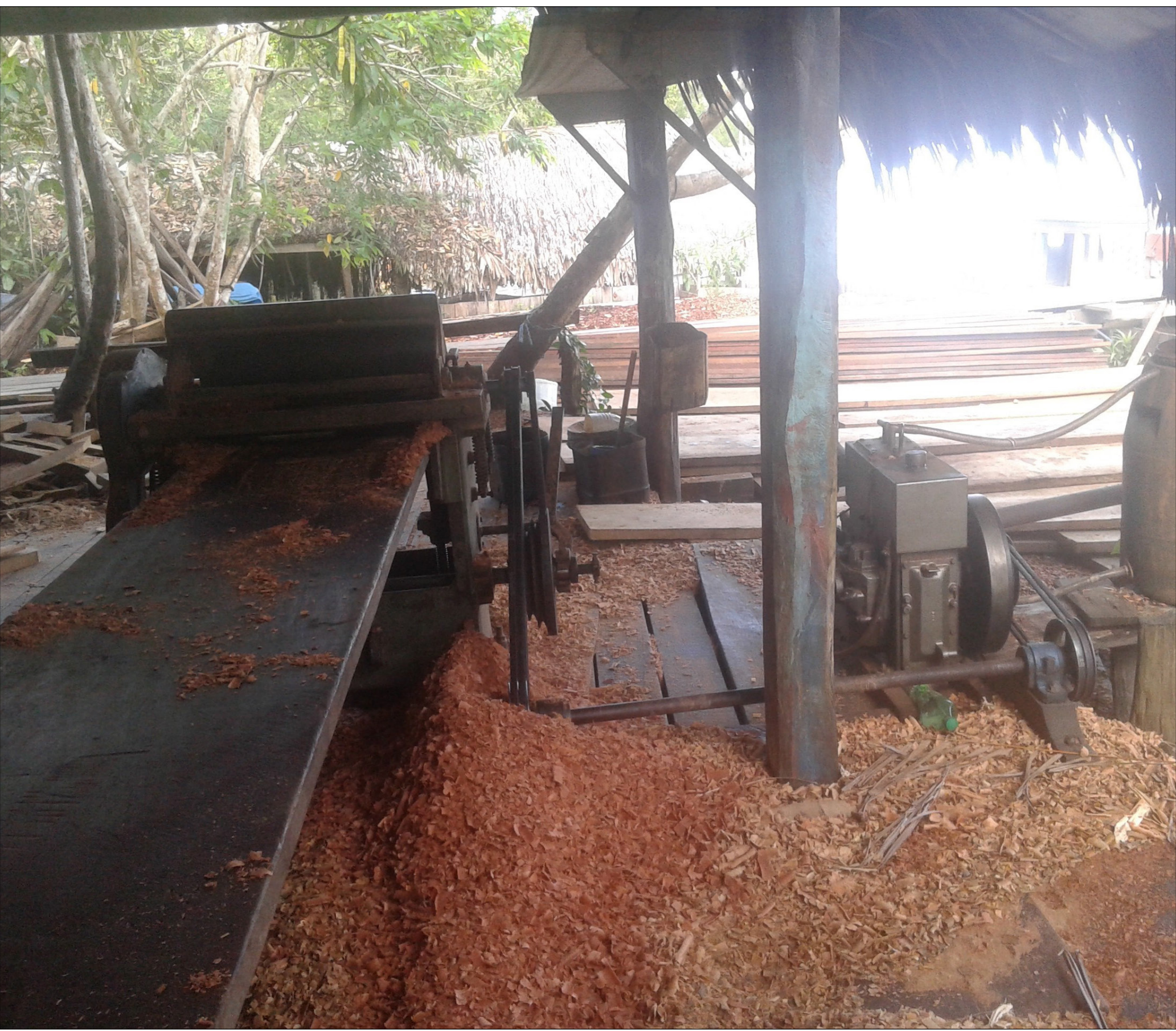

Figura 3 - Plainadora elétrica usada para fazer o polimento das madeiras empregadas na fabricação das embarcações. O equipamento funciona acoplado a um motor gerador de energia.

Foto: Rosenildo da Costa Pereira (25 nov. 2018). 


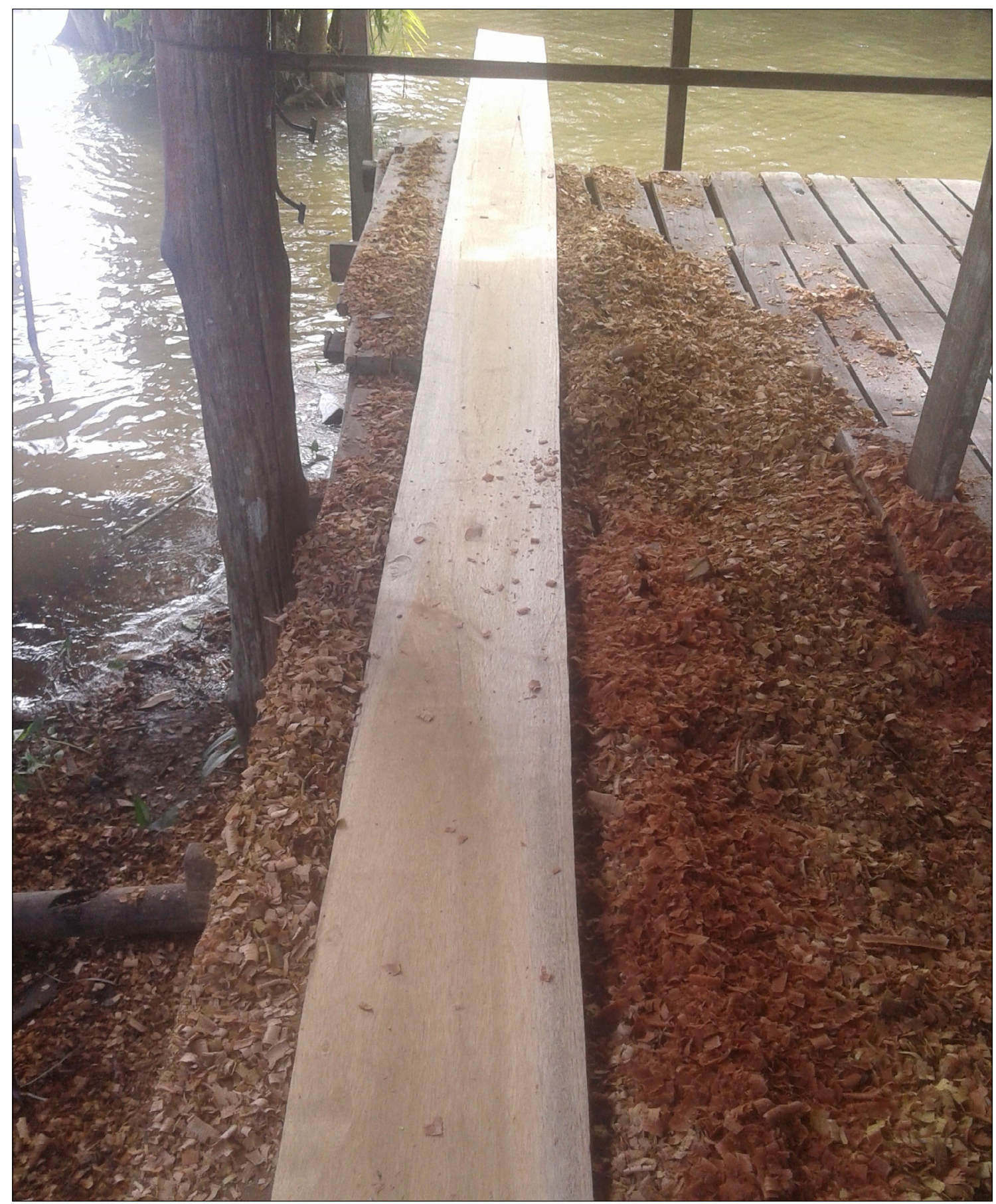

Figura 4 - Madeira polida após passar pela plainadora elétrica. Foto: Rosenildo da Costa Pereira (25 nov. 2018). 


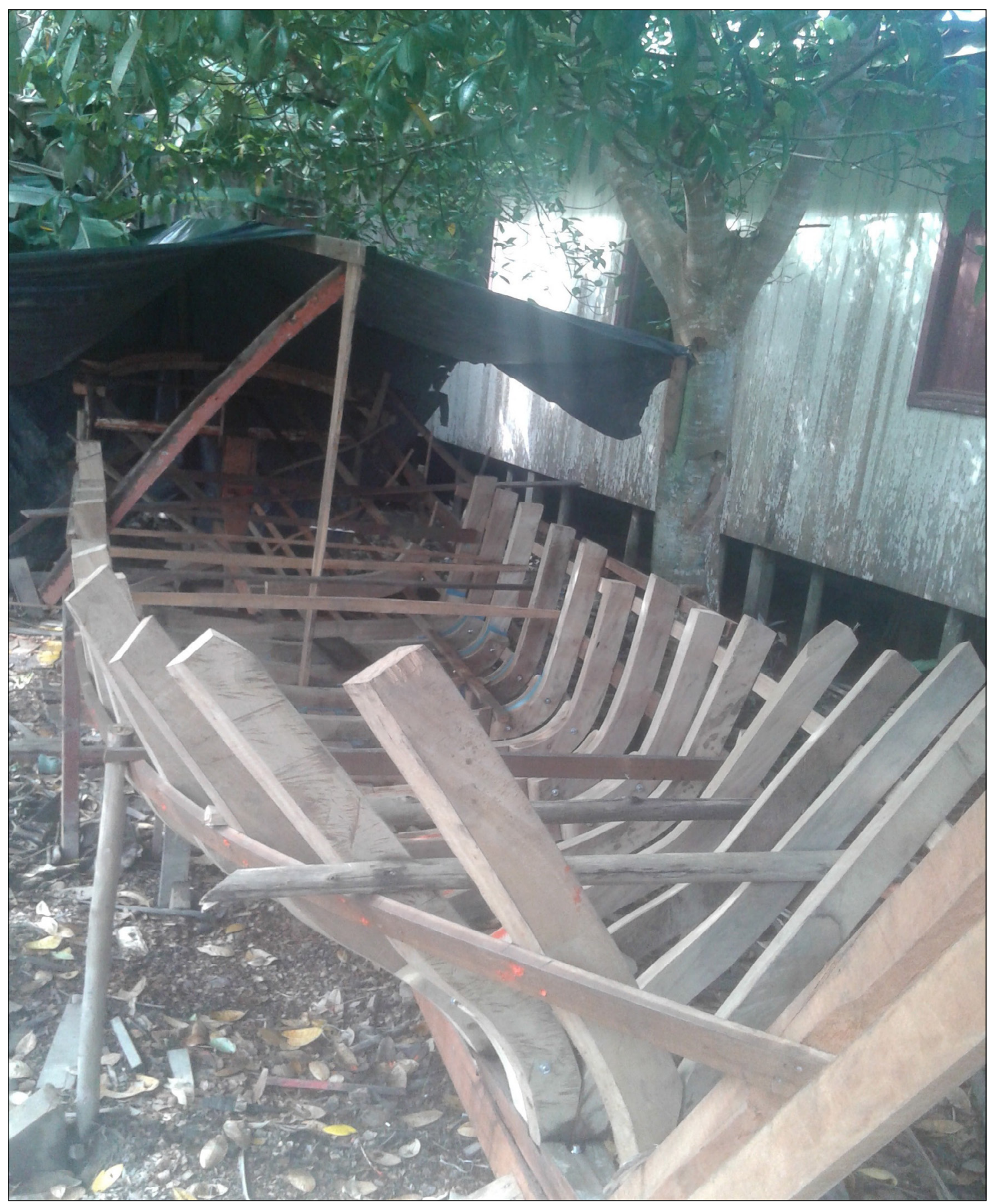

Figura 5 - Barco em construção.

Foto: Rosenildo da Costa Pereira (25 nov. 2018). 


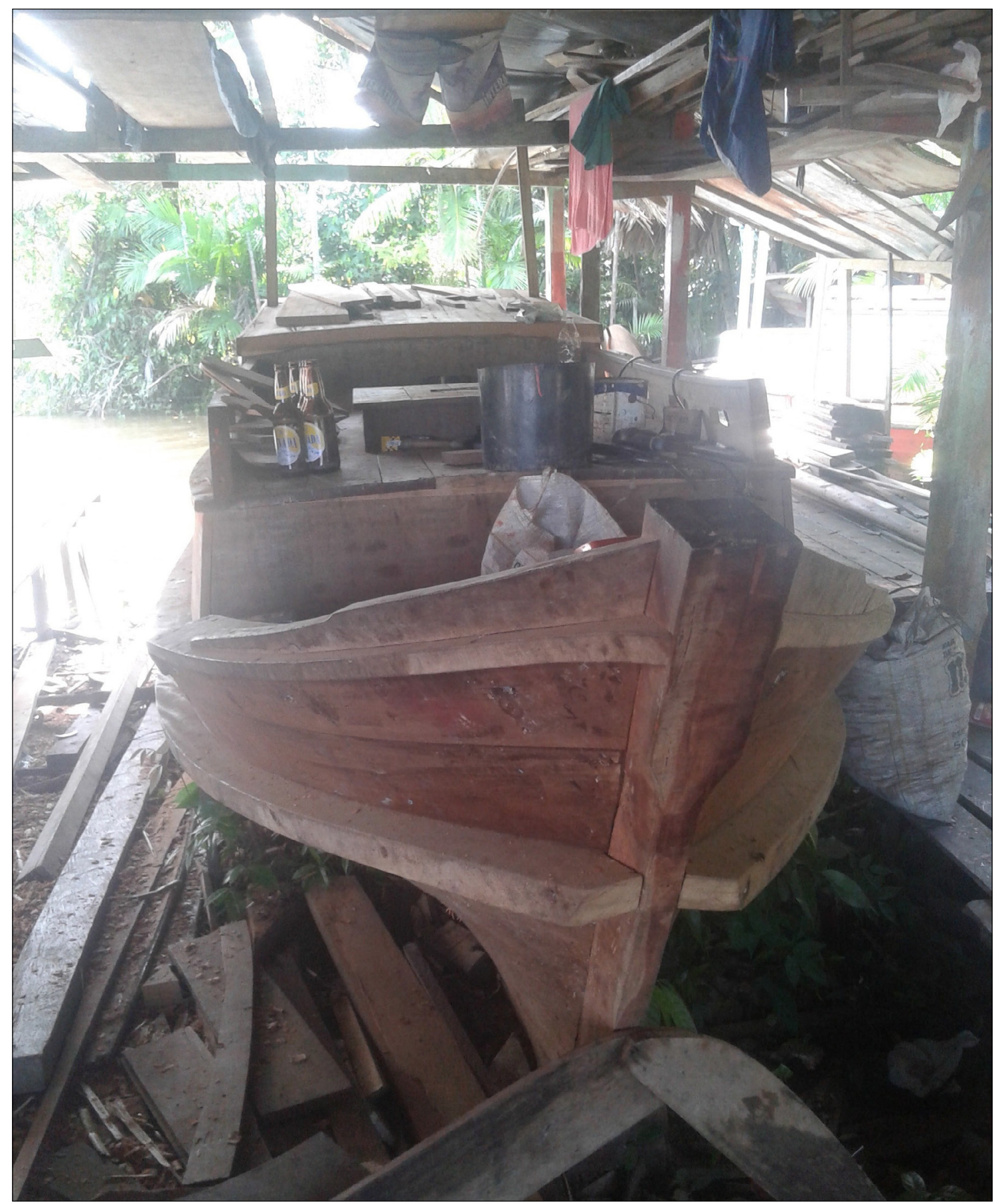

Figura 6 - Barco construído.

Foto: Rosenildo da Costa Pereira (25 nov. 2018). 


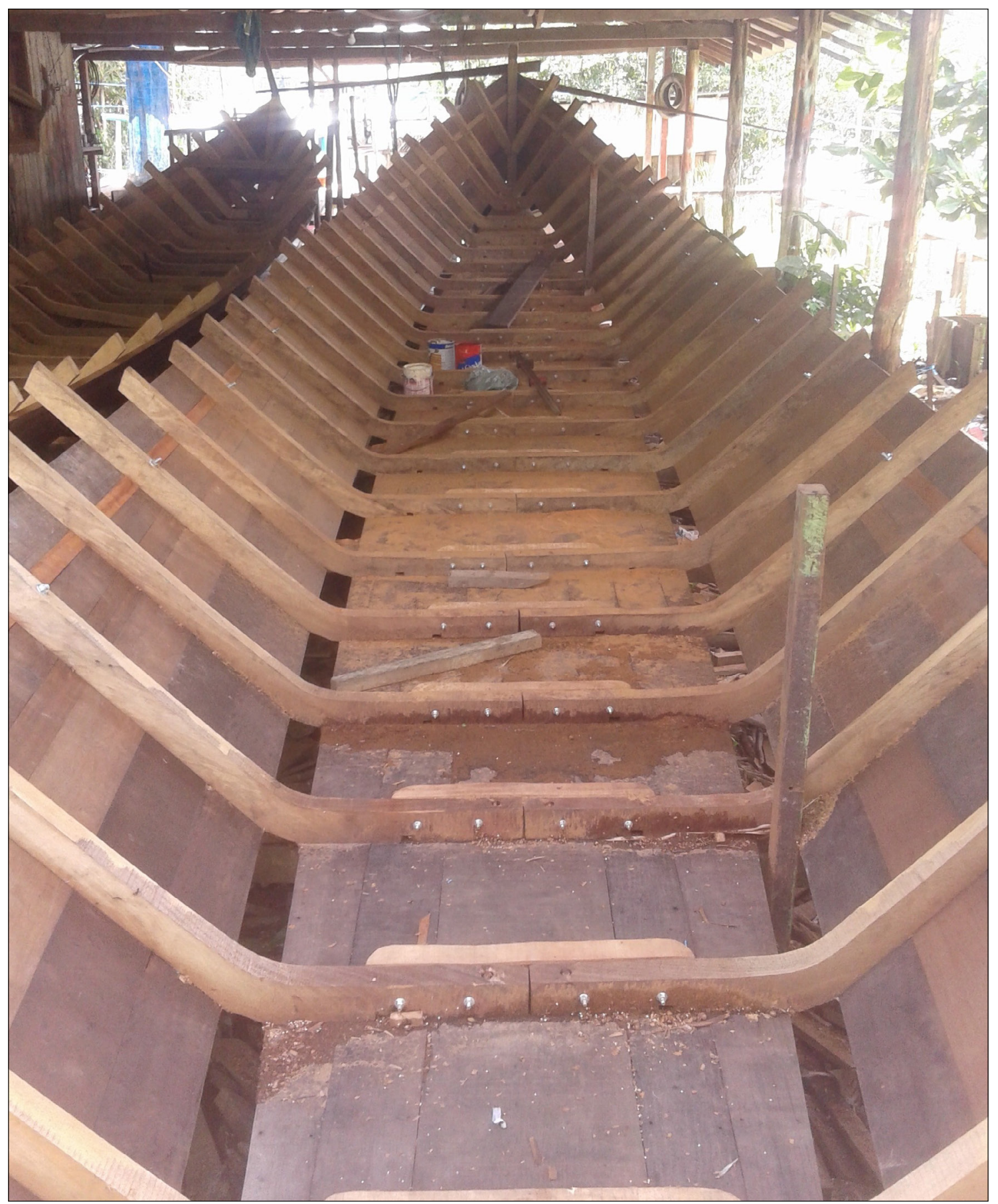

Figura 7 - Rabetas em fase de construção.

Foto: Rosenildo da Costa Pereira (25 nov. 2018). 


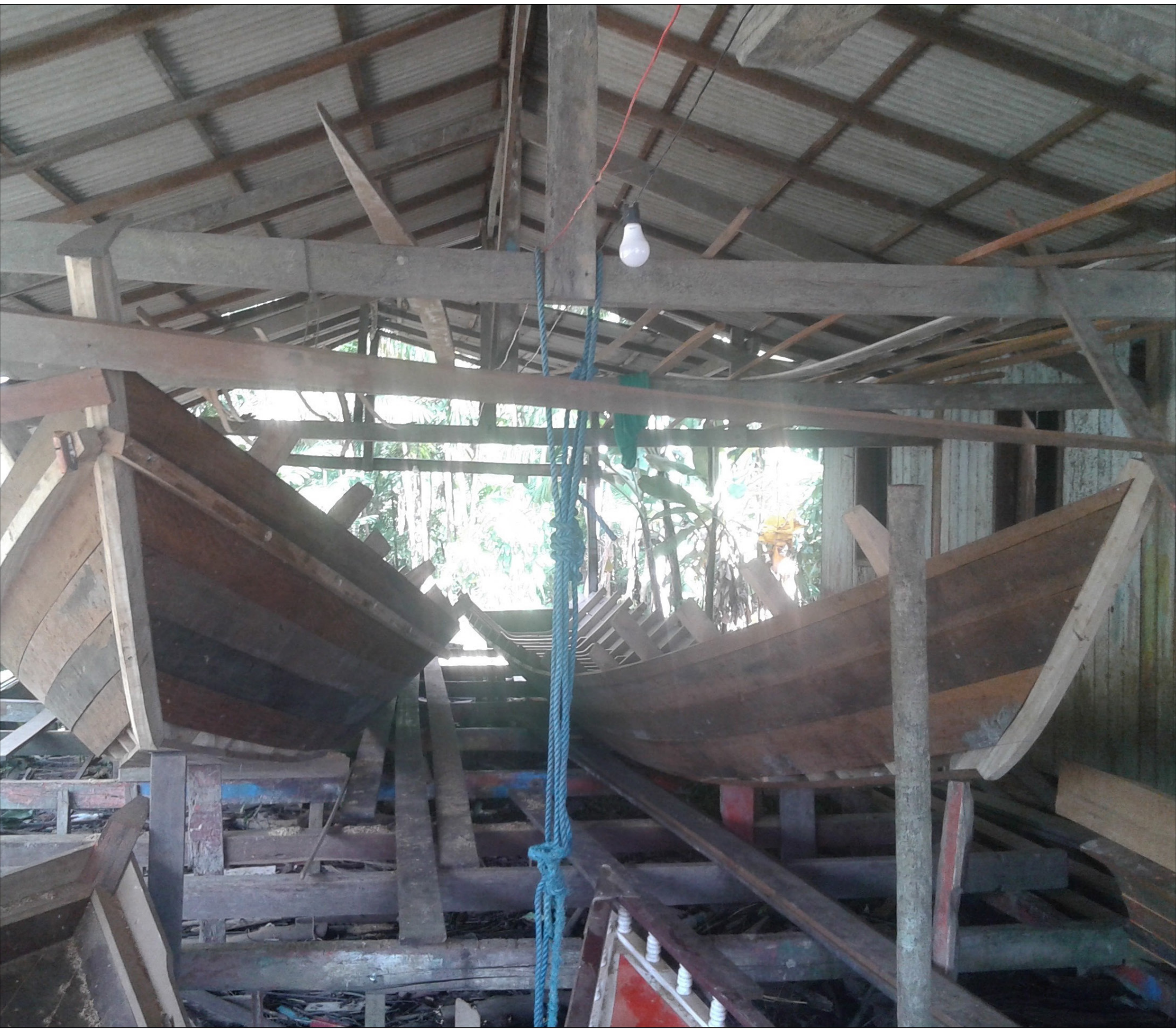

Figura 8 - Rabetas em fase de construção.

Foto: Rosenildo da Costa Pereira (25 nov. 2018). 


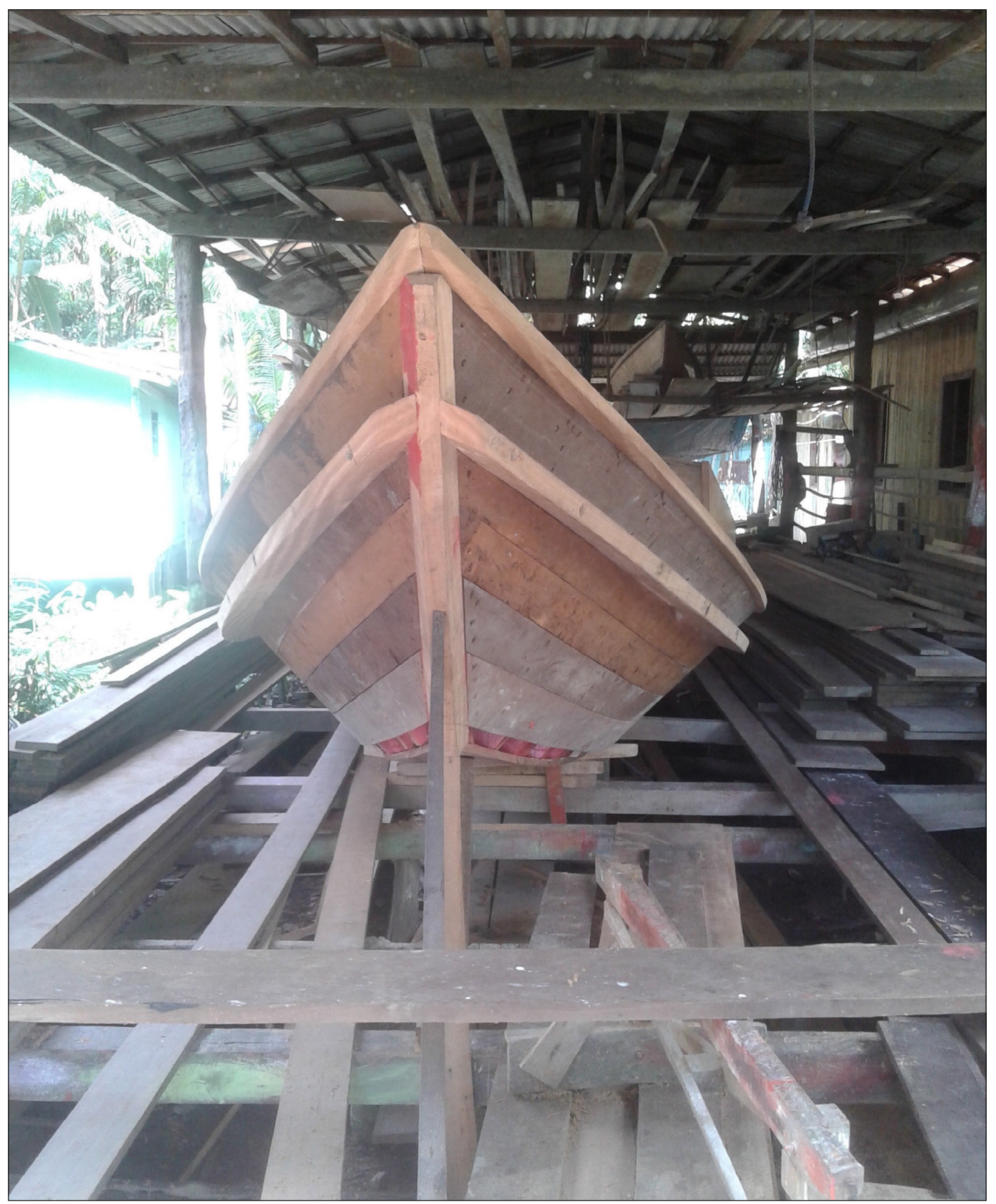

Figura 9 - Rabeta em fase construção.

Foto: Rosenildo da Costa Pereira (25 nov. 2018). 


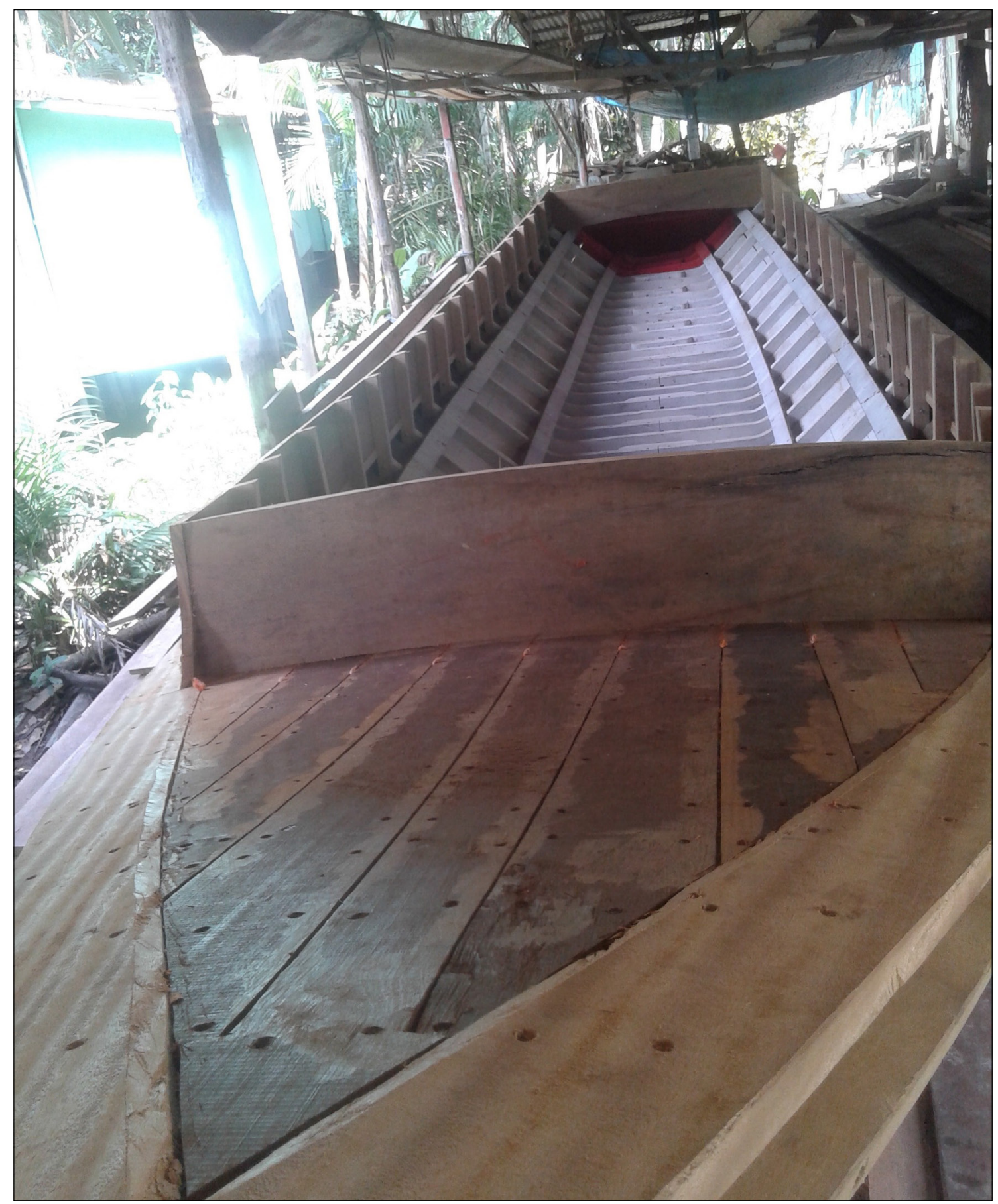

Figura 10 - Rabeta em fase de construção.

Foto: Rosenildo da Costa Pereira (25 nov. 2018). 


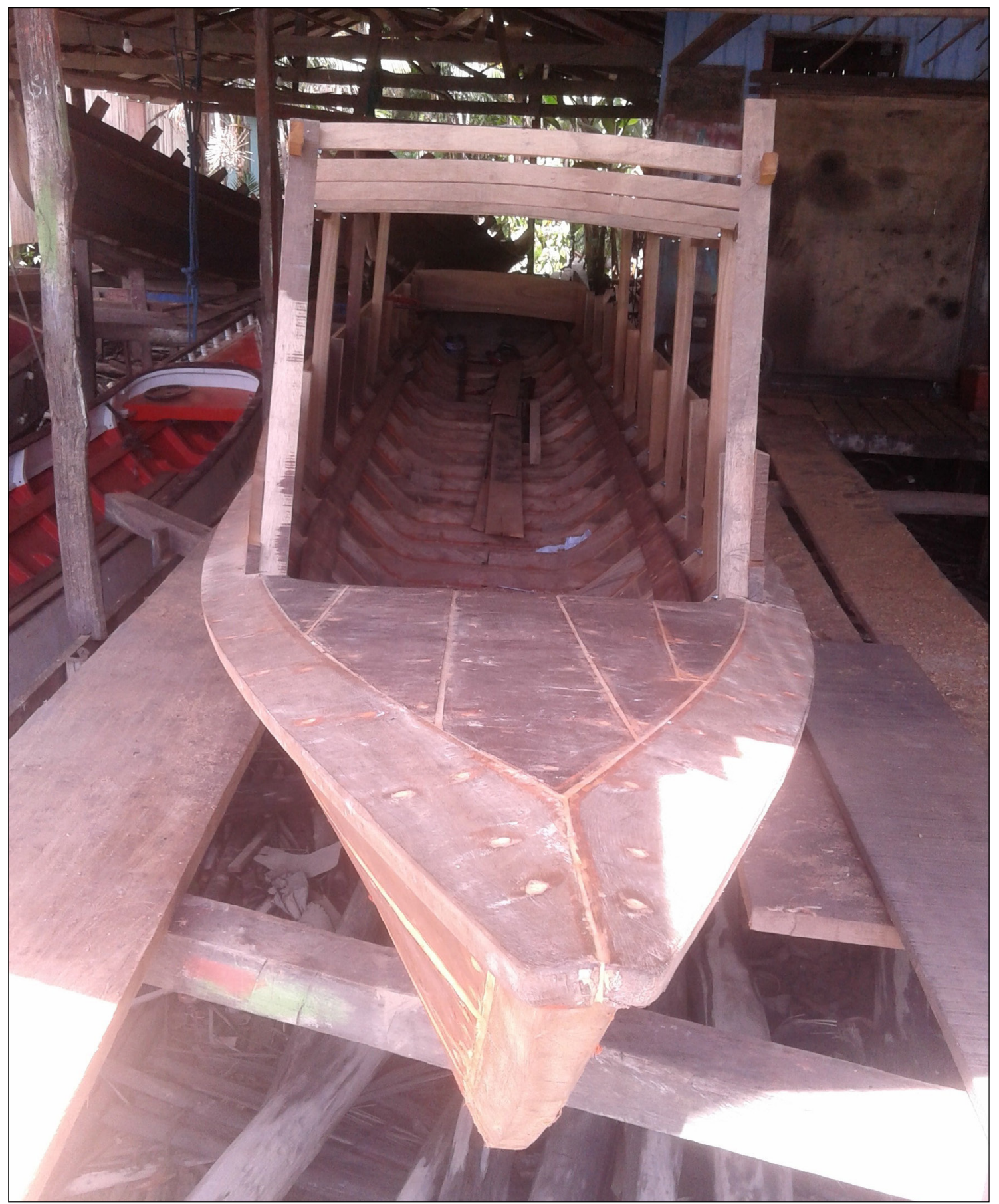

Figura 11 - Rabeta em fase de construção.

Foto: Rosenildo da Costa Pereira (25 nov. 2018). 


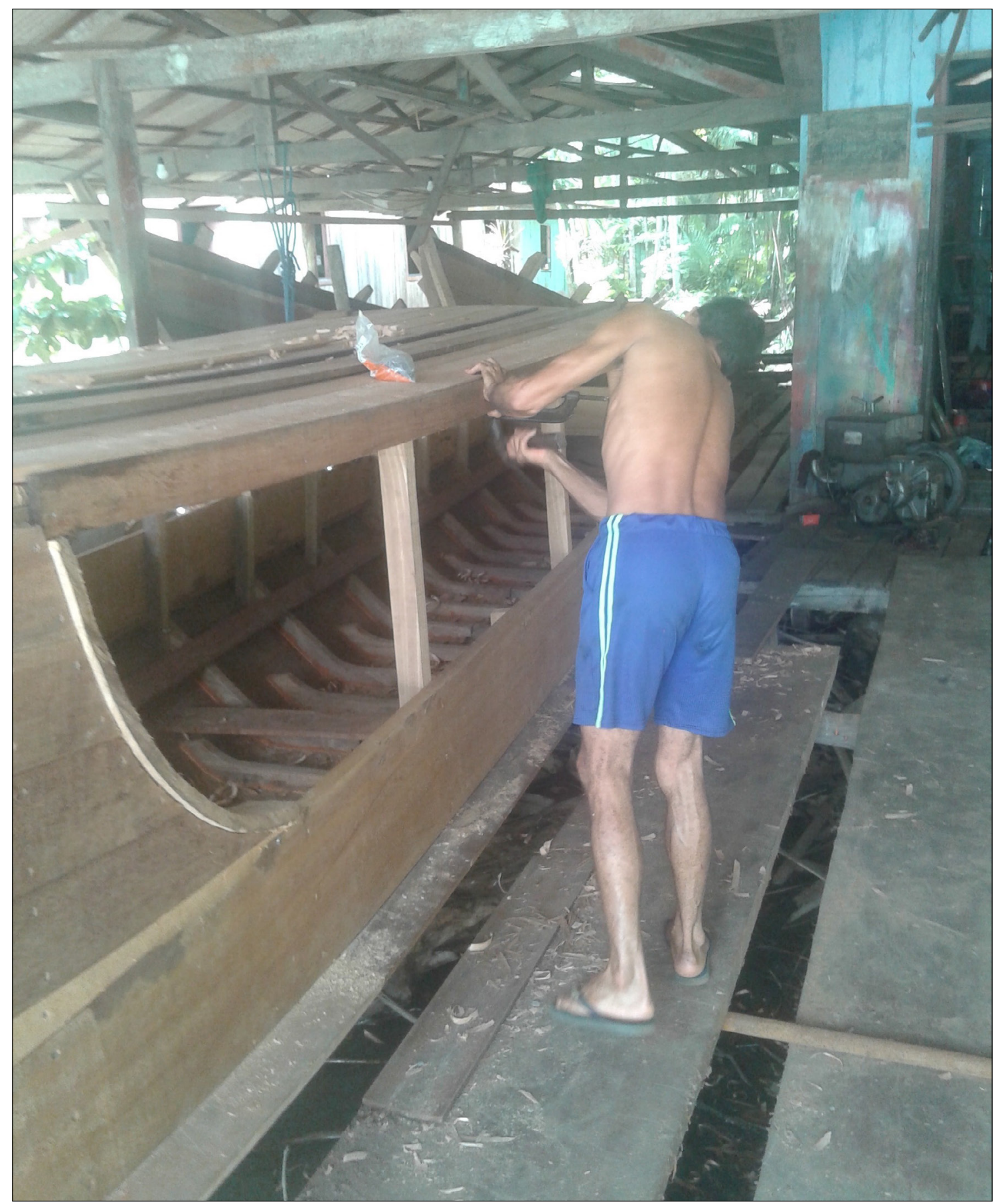

Figura 12 - Rabeta em fase de construção.

Foto: Rosenildo da Costa Pereira (25 nov. 2018). 


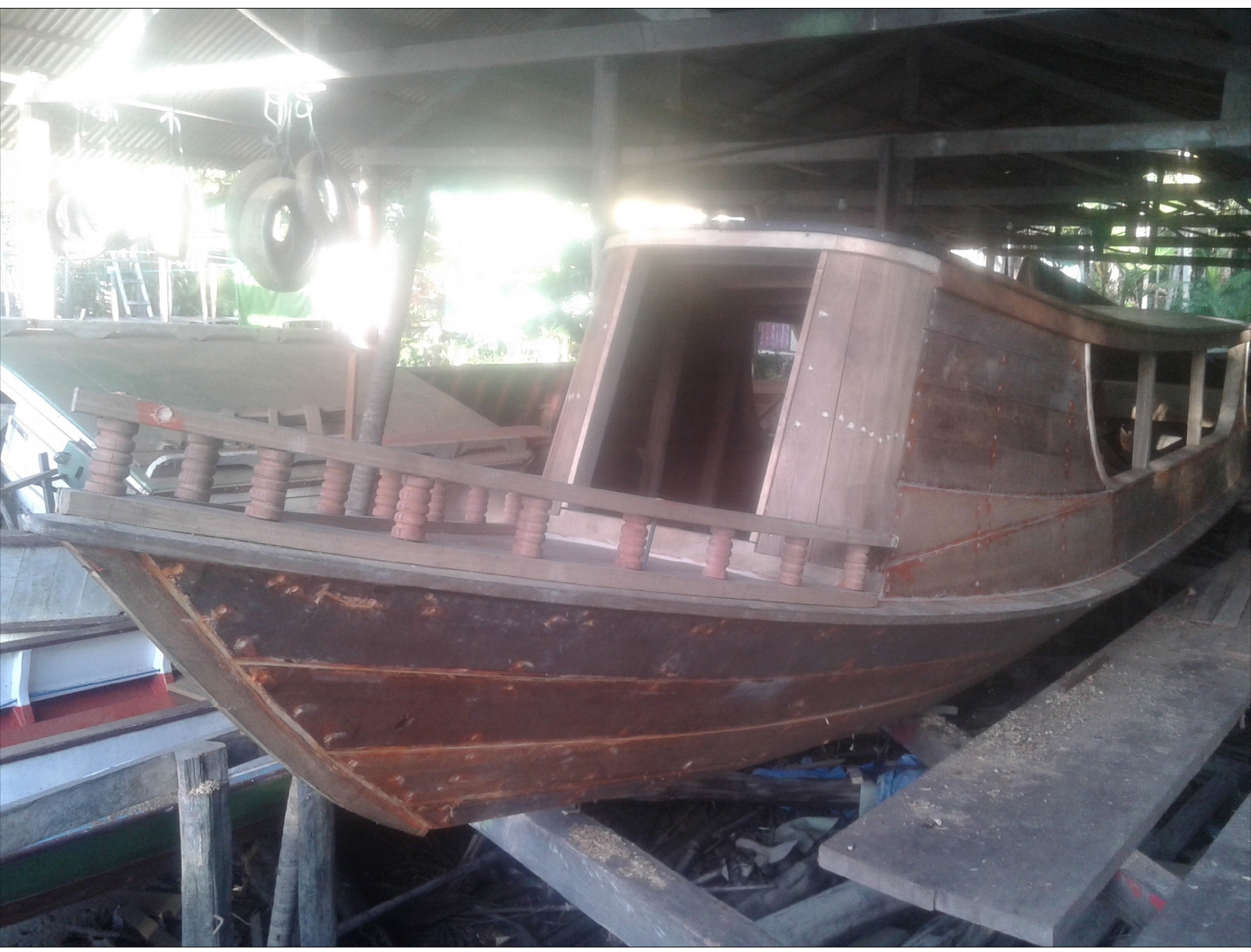

Figura 13 - Rabeta pronta após serviço de carpintaria. Foto: Rosenildo da Costa Pereira (25 nov. 2018). 


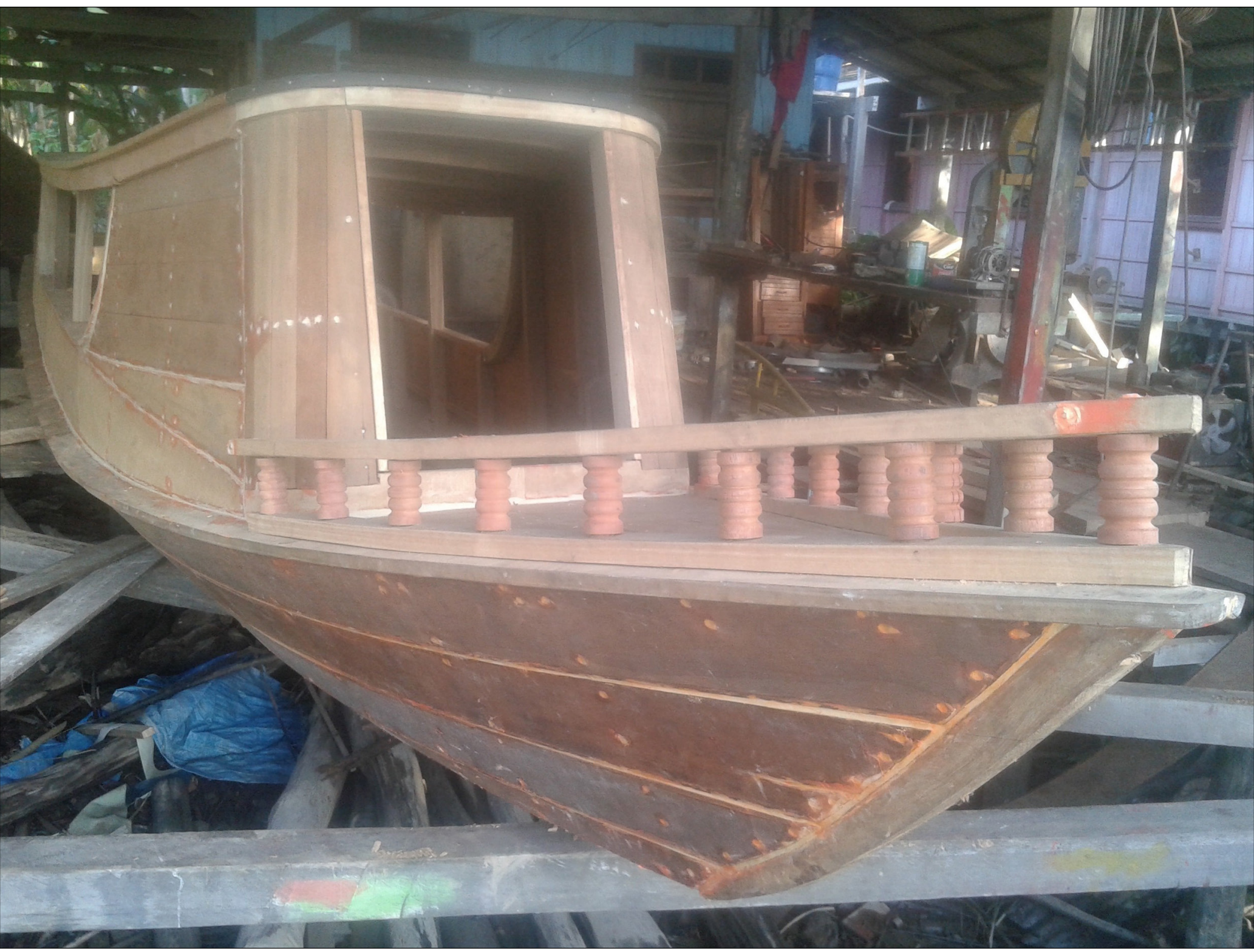

Figura 14 - Rabeta pronta após serviço de carpintaria. Foto: Rosenildo da Costa Pereira (25 nov. 2018). 